\title{
Preface
}

\section{A brief guide to Landscape Genetics}

\author{
Rolf Holderegger and Helene H. Wagner* \\ WSL Swiss Federal Research Institute, Zürcherstrasse 111, CH-8903 Birmensdorf, Switzerland; *Author for \\ correspondence (e-mail: helene.wagner@wsl.ch)
}

Received 30 November 2005; accepted in revised form 18 December 2005

\section{What is landscape genetics?}

In their inaugural paper, Manel et al. (2003) defined landscape genetics as a combination of landscape ecology and population genetics. In more detail, these authors stated that landscape genetics 'aims at providing information about the interaction between landscape features and microevolutionary processes, such as gene flow, genetic drift and selection' (Manel et al. 2003, p. 189). The first lesson to learn from this is that we are dealing with microevolution, i.e., evolutionary processes within species. Second, we are talking about gene flow and selection, two ecological and evolutionary processes that need different genetic approaches to be investigated Holderegger et al. 2006). Third, Manel et al. (2003, p. 190) remarked that 'the two key steps of landscape genetics are the detection of genetic discontinuities and the correlation of these discontinuities with landscape environmental features, such as barriers', which provides relevant information for various scientific disciplines such as evolution, ecology or conservation biology. Hence, we need two data sets, a genetic one and a landscape ecological one, and we look for breaks, gradients or transitions that coincide in these two data sets. Manel et al. (2003) were less explicit in their landscape definition, and landscape ecologists are well aware that this is a difficult task (Turner et al. 2001). Thus, the definition of landscape genetics by Manel et al. (2003) was much clearer on the population genetic than on the landscape ecological side, including spatial scale.
A pragmatic circumscription of landscape genetics could be that landscape genetics endorses those studies that combine population genetic data, adaptive or neutral, with data on landscape composition and configuration, including matrix quality. A comparison with metapopulation biology and metapopulation genetics may clarify the major characteristic of landscape genetics. Classical metapopulation studies are spatially implicit, they view the natural world as divided into cheerful islands (patches) and hostile sea (matrix) (Baquette 2004). Spatially realistic metapopulation models typically consider the geographic distance between patches (Ovaskainen and Hanski 2004), but do not include matrix quality. In landscape genetics, however, the landscape with its composition, spatial configuration and dynamics makes up half of the story beside genetics. Landscape genetics therefore is much closer to the real world than the classical metapopulation concept. For instance, the actual connectivity of populations in terms of dispersal of organisms may deviate markedly from an abstract population genetic gene flow index (Whitlock and McCauley 1999) or from a landscape ecological connectivity index calculated from a habitat map ( $\mathrm{Li}$ and $\mathrm{Wu} 2004)$. Landscape genetics provides powerful tools for quantifying such processes in real landscapes. While population geneticists have eagerly adopted this approach, landscape ecologists have only started using genetic methods.

Landscape genetics is an important emerging research topic that integrates landscape pattern with population genetics. It is a new way of sci- 
entific thinking, whereas there exists neither a specific landscape genetic theory nor specific concepts. While landscape ecology partly shares these limitations ( $\mathrm{Wu}$ and Hobbs 2002), the situation is different with population genetics, which has a well-founded theoretical basis (Hartl and Clark 1997). However, no landscape genetic research agenda has been defined to date, and landscape genetic data are still scarce.

We believe that the benefit of landscape genetics lies in its heuristic, as well as practical, values of forcing landscape ecologists to think more about processes rather than spatial patterns, and to remind population geneticists that processes are affected by the quality of a landscape and not just by pure spatial distance (Holderegger et al. in press). This is new, especially when it comes to scientific practice.

\section{Special section on landscape genetics}

The following collection of papers, partly originating from a symposium held at the 2005 USIALE meeting in Syracuse, NY (USA), aims at providing an introduction to the genetic background of landscape genetics, giving examples of landscape ecological applications and pointing to methodological problems of landscape genetics. The papers address the broader audience of landscape ecologists rather than specialists and should serve as an entry point to landscape genetics for landscape ecologists.

The first two papers deal with basic genetic topics. The first article by Holderegger et al. (2006) introduces some genetic principles as well as neutral and adaptive genetic diversity and further points to caveats and limitations of the use of genetic data. The properties of different genetic markers that can be used to investigate different processes at various spatio-temporal scales are then discussed by Latta (2006). How population genetic methods can be applied to study two principal ecological processes that are closely related to landscape ecology, namely migration, or gene flow in genetic terms, and metapopulation dynamics, is the topic of the following two contributions. Sork and Smouse (2006) provide a genetic analysis of landscape connectivity by means of gene flow assessment using tree populations as model systems, while Pannell and Dorken (2006) evaluate the role of colonization in plant metapopulations and its influence on range expansion. Subsequently, Wagner et al. (2006) give an example of a simulation approach in landscape genetics using both habitat data and genetic data of an epiphytic lichen in a dynamic landscape. Finally, Antolin et al. (2006) show how landscape features affect the distribution of genetic variation in colonies of prairie dogs. The special section is complemented by three contributed research papers describing applications of landscape genetics in animals, (i.e.,) an insect (Holzhauer et al. 2006), a fish (Neville et al. 2006) and a mammal (Broquet et al. 2006).

\section{Perspective}

Landscape genetics is a current scientific trend. During the last 15 years, the papers that interpreted genetic data in relation to landscape features steadily increased in numbers (grey line in Figure 1). Since the seminal paper of Manel et al.

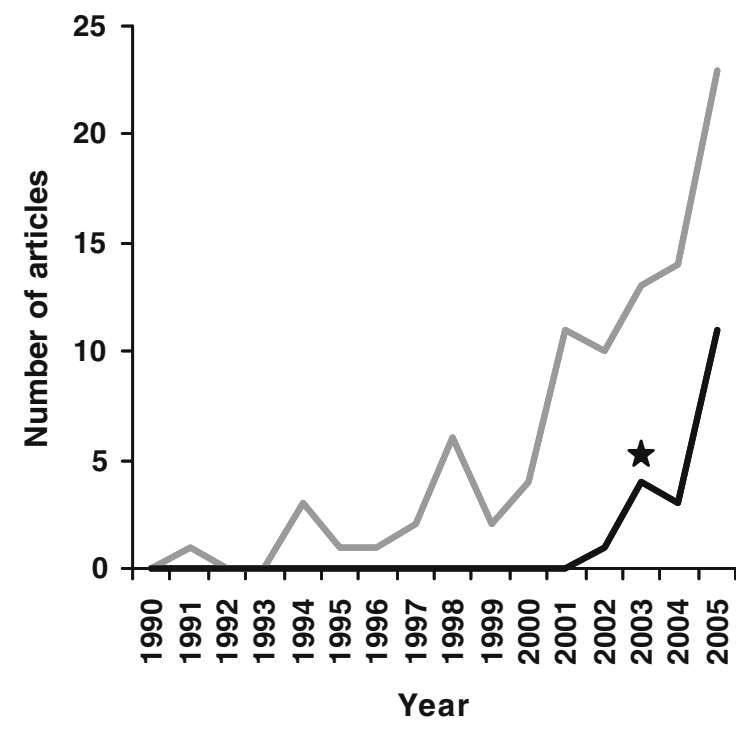

Figure 1. Landscape genetics is a current scientific trend. Results of an ISI Web of Science search for articles relating genetic results to landscape features (search criterion: Landscape AND Genetics; grey line) or explicitly referring to landscape genetics (search criterion: Landscape Genetics; black line) during the years 1990-2005 (January-September). Note that the articles within the second category are included in those of the first category. The asterisk denotes the publication year of the seminal article by Manel et al. (2003). 
(2003), landscape genetic studies are strongly on the rise (black line in Figure 1), although the term had been used before. What makes landscape genetics so attractive to researchers? We believe that the major driver of this interest is the possibility to investigate a process through genetic data and to analyse how this process works in the real world by assessing landscape ecological data.

We hope that this special section will help landscape ecologists to better understand and use modern molecular genetic methods. It is new to use molecular genetic data to test specific landscape ecological hypotheses concerning the effect of landscape structure on the actual movement of organisms, the connectivity of habitats from an organism's perspective or the effect of disturbance and landscape dynamics on metapopulation dynamics. Thus we provide a list of suggestions for landscape ecologists who want to conduct such landscape genetics research (Table 1). On the other hand, we also believe that it is necessary to explain to population geneticists the wealth of analyses that can be done with landscape ecolog- ical data. Table 2 summarizes some key issues that population geneticists should consider when incorporating landscape ecology in their analyses. Only if we combine concepts and methods from both fields correctly and to their full potential will landscape genetics become a fruitful scientific approach of the future.

\section{Acknowledgements}

We thank Felix Gugerli and Jingle Wu for comments on this manuscript and the many referees that reviewed the articles of this special section. This work was partly funded by the Swiss National Science Foundation within the NCCR Plant Survival.

\section{References}

Antolin M.F., Savage L.T. and Eisen R.J. 2006. Landscape features influence genetic structure of Black-Tailed Prairie Dogs (Cynomys ludovicianus). Landsc. Ecol. 21: 867-875.

Table 1. Dos and don'ts for landscape ecologists who want to use genetics.

(1) Do not try to do it all alone: collaborate with population geneticists and invest time in developing a common ground, as it is necessary in any interdisciplinary project (Holderegger et al. 2006)

(2) Be aware of what genetic data mean; do not confound neutral and adaptive genetic variation (Holderegger et al. 2006)

(3) Population genetics offers the possibility to investigate different time scales (from evolutionary time spans to the current year); do not confound recent and historic gene flow (Latta 2006; Pannell and Dorken 2006; Sork and Smouse 2006)

(4) Distinguish between biparentally inherited DNA and uniparentally inherited DNA that come from either the father, the mother or both, and consider their respective mode of dispersal by seed and/or pollen (Latta 2006; Sork and Smouse 2006)

(5) Test hypotheses; make it a truly landscape-related hypothesis, e.g., the effect of landscape structure or landscape dynamics on connectivity (Neville et al. 2006; Wagner et al. 2006)

(6) Make sure you choose the appropriate landscape and organism to test your hypothesis; check whether suitable genetic markers already exist or can easily be developed (Antolin et al. 2006; Latta 2006)

Table 2. Landscape ecological advice for population geneticists.

(1) A GIS is more than a tool for mapping populations; GIS combines a spatial data base with tools for data management, analysis and visualisation. For example, it contains flexible methods for calculating cost-distance functions, i.e., modifying Euclidean distance estimates with information on matrix traversability or resistance based on environmental data (Broquet et al. 2006)

(2) A landscape approach should go beyond testing the effect of distance (e.g., isolation by distance); use pure distance as a null model and then test for quantitative or qualitative matrix effects (Antolin et al. 2006; Neville et al. 2006)

(3) Landscapes can rarely be assumed constant; disturbance and landscape change can be incorporated into the study design (Holzhauer et al. 2006; Wagner et al. 2006)

(4) Replication at the landscape level is often problematic or simply not possible; simulation modelling may help establishing a mechanistic link (Wagner et al. 2006)

(5) The spatial and temporal variability of site conditions may be as important for explaining quantitative traits as are differences in their mean (Antolin et al. 2006; Holzhauer et al. 2006) 
Baquette M. 2004. The classical metapopulation theory and the real, natural world: a critical appraisal. Basic Appl. Ecol. 5: 213-224.

Broquet T., Ray N., Petit E., Fryxell J.M. and Burel F. 2006. Genetic isolation by distance and landscape connectivity in the American Marten (Martes americana). Landsc. Ecol. 21: $877-889$.

Hartl D.L. and Clark A.G. 1997. Principles of Population Genetics. Sinauer, Sunderland.

Holderegger R., Gugerli F., Scheidegger F. and Taberlet P. In press. Integrating population genetics with landscape ecology to infer spatio-temporal processes. In: Kienast F., Gosh R. and Wildi O. (eds), A Changing World: Challenges for Landscape Research. Kluwer, Dordrecht.

Holderegger R., Kamm U. and Gugerli F. 2006. Adaptive versus neutral genetic diversity: implications for landscape genetics. Landsc. Ecol. 21: 797-807.

Holzhauer S.I.J., Ekschmitt K., Sander A.-C., Dauber J. and Wolters V. 2006. Effect of historic landscape change on the genetic structure of the bush-cricket Metrioptera roeseli. Landsc. Ecol. 21: 891-899.

Latta R. 2006. Integrating patterns across multiple genetic markers to infer spatial processes. Landsc. Ecol. 21: 809-820.

$\mathrm{Li} \mathrm{H}$. and $\mathrm{Wu} \mathrm{J}$. 2004. Use and misuse of landscape indices. Landsc. Ecol. 19: 389-399.

Manel S., Schwartz M.K., Luikart G. and Taberlet P. 2003. Landscape genetics: combining landscape ecology and population genetics. Trends Ecol. Evol. 18: 189-197.
Neville H.M., Dunham J.B. and Peacock M.M. 2006. Landscape attributes and life history variability shape genetic structure of trout populations in a stream network. Landsc. Ecol. 21: 901-916.

Ovaskainen O. and Hanski I. 2004. Metapopulation dynamics in highly fragmented landscapes. In: Hanski I.A. and Gaggiotti O.E. (eds), Ecology, Genetics and Evolution of Metapopulations. Academic Press, Amsterdam, pp. 73-103.

Pannell J.R. and Dorken M. 2006. Colonisation as a common denominator in plant metapopulations and range expansions: effects on genetic diversity and sexual systems. Landsc. Ecol. 21: 837-848.

Sork V.L. and Smouse P.E. 2006. Genetic analysis of landscape connectivity in tree populations. Landsc. Ecol. 21: 821-836.

Turner M.G., Gardner R.H. and O'Neill R.V. 2001. Landscape Ecology in Theory and Practice. Springer, New York.

Wagner H.H., Werth S., Kalwij J.M., Bolli J.C. and Scheidegger C. 2006. Modelling forest recolonization by an epiphytic lichen using a landscape genetic approach. Landsc. Ecol. 21: 849-865.

Whitlock M.C. and McCauley D.E. 1999. Indirect measures of gene flow and migration: $F_{\mathrm{ST}} \neq 1 /(4 \mathrm{Nm}+1)$. Heredity 82 : $117-125$.

Wu J. and Hobbs R. 2002. Key issues and research priorities in landscape ecology: an idiosyncratic synthesis. Landsc. Ecol. 17: $355-365$. 